(C) 2005 American Chemical Society, Anal. Chem., Orendorff ac0511795 Supporting Info Page 1

Anal. Chem.,

\title{
Alkylsilane-Based Stationary Phases via a Displaceable Surface Template Approach: Synthesis, Characterization, and Chromatographic Performance
}

\author{
Christopher J. Orendorff ${ }^{\ddagger}$ and Jeanne E. Pemberton, ${ }^{*}$ \\ Department of Chemistry \\ University of Arizona \\ 1306 East University Boulevard \\ Tucson, AZ 85721
}

${ }^{\ddagger}$ Current address: University of South Carolina, Department of Chemistry and Biochemistry, 631 Sumter St., Columbia, SC 29208

*Author to whom correspondence should be addressed: pembertn@u.arizona.edu, (520) 6218245 
(C) 2005 American Chemical Society, Anal. Chem., Orendorff ac0511795 Supporting Info Page 2

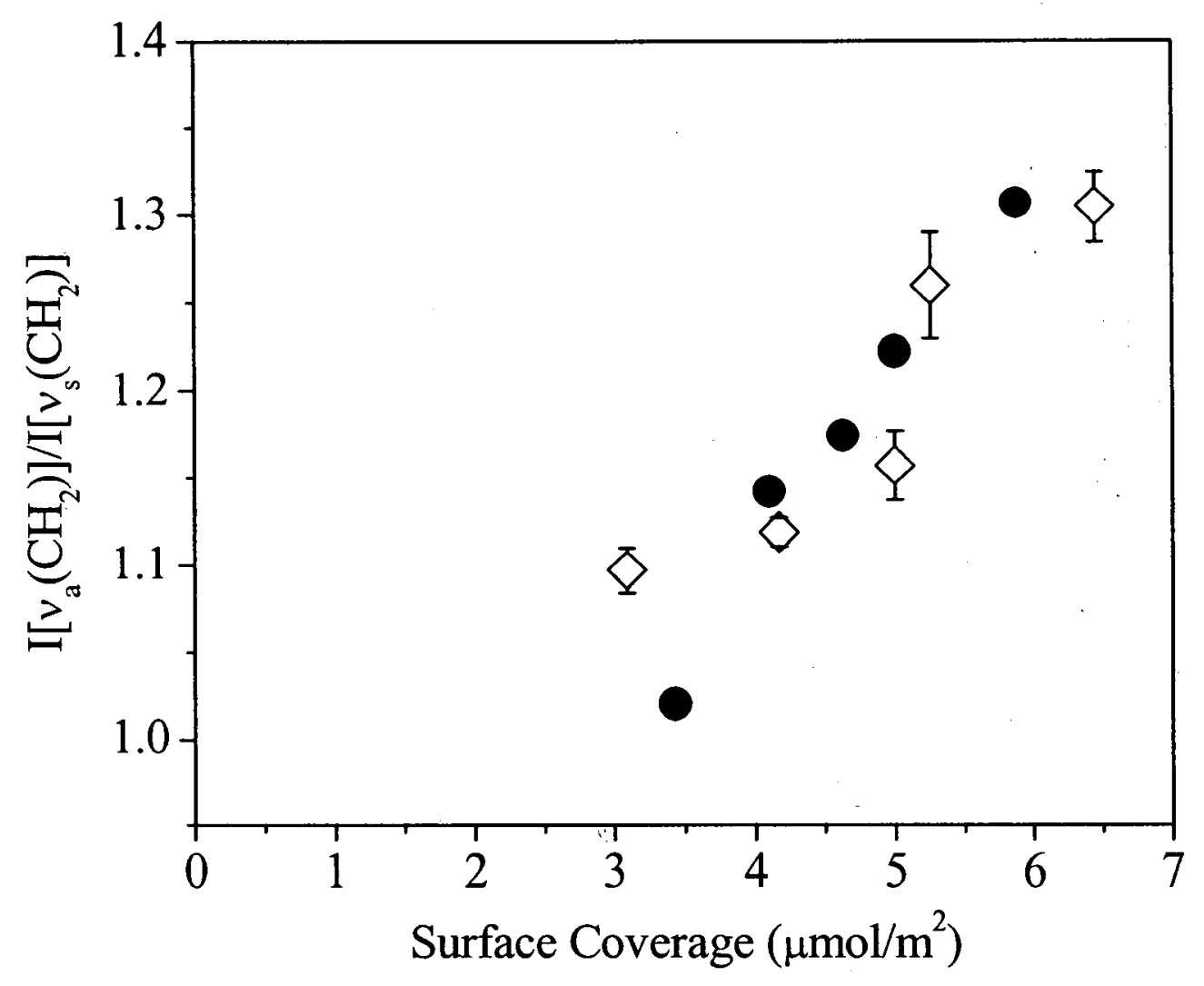

Figure 1S: $\mathrm{I}\left[v_{\mathrm{a}}\left(\mathrm{CH}_{2}\right)\right] / \mathrm{I}\left[\nu_{\mathrm{s}}\left(\mathrm{CH}_{2}\right)\right]$ as a function of $\mathrm{C}_{18}$ surface coverage $\left(\mu \mathrm{mol} / \mathrm{m}^{2}\right)$ for III-1 and IV phases $(\bullet)$ and NIST $\mathrm{C}_{18}$ phases $(\diamond)$ from reference 11. 
(C) 2005 American Chemical Society, Anal. Chem., Orendorff ac0511795 Supporting Info Page 3

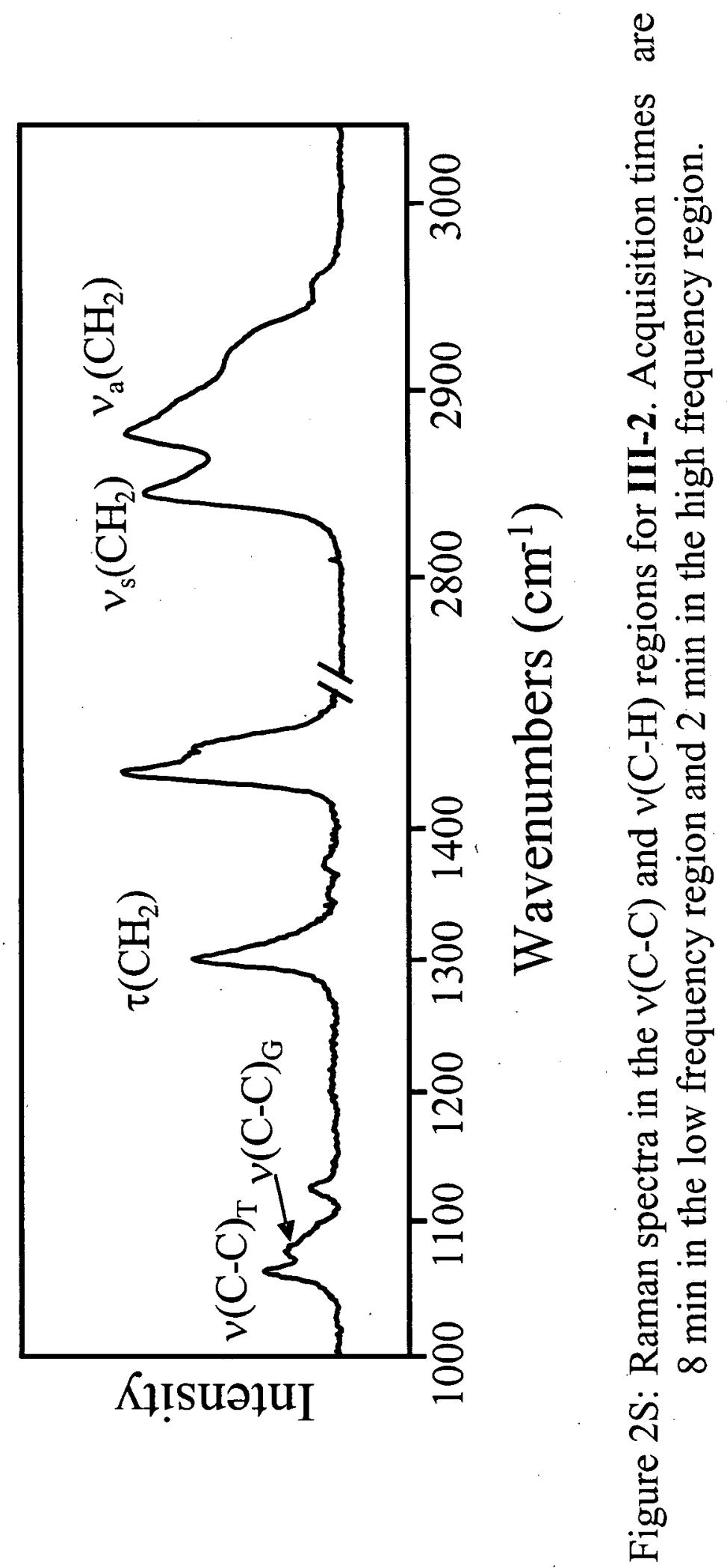

